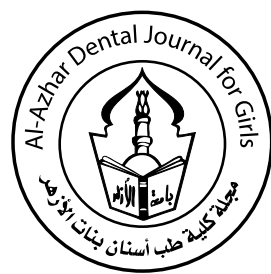

\title{
Tensile Strength of Denture Base Material Reinforced With Zirconia Nanoparticle and Glass Fibers
}

\author{
Mohammed M Gad ${ }^{(1)}$, Ahmed Rahoma ${ }^{(2,3)}$, Reem Abualsaud ${ }^{(4)}$ and Mahmoud M Ammar ${ }^{(5)}$
}

Codex : 33/1807

azhardentj@azhar.edu.eg

http://adjg.journals.ekb.eg

\section{KEYWORDS}

Acrylic denture base,

Tensile strength,

Glass fiber,

Zirconia nanoparticles

\begin{abstract}
Purpose: The current study was conducted to determine the effect of hybrid reinforcement with zirconium oxide nanoparticles (NZ) and glass fibers (GF) on the tensile strength of denture base resin. Materials and methods: Different ratios of NZ/ GF were added into resin at a fixed concentration of $5 \%$ by weight. For each formulation (one control and 7 experimental groups), ten specimens were prepared in a dumbbell shape using a stainless steel mold. Tensile strength was evaluated by using a universal testing machine. Scanning electron microscope (SEM) was used to study the fractured surfaces. Results: Tensile strength of the specimens reinforced with NZ/GF in varying ratios was found to be higher than that of the control group. Among the hybrid groups, the specimens reinforced with $50 \% \mathrm{NZ}-50 \% \mathrm{GF}$ showed the highest tensile strength. SEM fractographs showed multiple lamellae displayed surface, which is characteristic of strong material. Weak adhesion and pull out of fibers from the matrix were seen in high concentration GF. Conclusion: The incorporation of 50\%NZ-50\%GF into acrylic denture base appeared to improve the tensile strength.
\end{abstract}

\section{INTRODUCTION}

Since early 1940s, polymethylmethacrylate (PMMA) remained as the principal material of choice for the denture base construction. PMMA stayed popular due to its favorable characteristics, low cost, ease of handling and processing as well as ability to repair. It provides

1. Lecturer, Department of Substitutive Dental Sciences, College of Dentistry, Imam Abdulrahman Bin Faisal University, P.O. Box 1982, Dammam 31411, Saudi Arabia

2. Lecturer, Department of Dental Biomaterials, College of Dentistry, Al-Azhar University, Assiut Branch, P.O. Box 11117, Egypt.

3. Assistant Professor, Department of Restorative Dental Sciences, College of Dentistry, Imam Abdulrahman Bin Faisal University, P.O. Box 1982, Dammam 31411, Saudi Arabia

4. Assistant Professor, Department of Substitutive Dental Sciences, College of Dentistry, Imam Abdulrahman Bin Faisal University, P.O. Box 1982, Dammam 31411, Saudi Arabia

5. Assistant Professor of Removable Prosthodontics, Faculty of Dental Medicine, Al-Azhar University, Assiut Branch. Egypt 
prosthesis with accurate fit and stability in the oral cavity. In addition to that, it provides an esthetic appearance ${ }^{(1,2)}$. However, there are still concerns when it comes to the strength and stiffness of this material. Denture fractures could result from the inherent mechanical properties of the denture base resin or as a result of oral anatomical variations such as increased ridge resorption, or deep incisal notching at the labial frena. Fracture may also occur at areas of sharp contours or profound scratches or as a result of induced processing stress ${ }^{(3,4)}$.

Over the years, multiple attempts have been made to improve the strength of PMMA and its performance thereafter. Those trials include a chemical approach involving copolymerization and crosslinking or a physical approach by reinforcement with different fibers ${ }^{(5)}$, or metal particles ${ }^{(6)}$. Out of these additions, glass fibers (GF) have received much attention ${ }^{(7)}$. Studies have shown that GFs had a significant positive effect when the proper fiber length and ratio is incorporated into the acrylic resin and adequate processing technique is employed ${ }^{(7,8)}$. Silanated GFs provide good adhesive properties to polymer matrix in addition to their esthetic qualities, which make them a good choice for dental applications ${ }^{(8)}$. Mechanically, it has been reported that GF improved properties of the denture base resins, particularly fatigue resistance ${ }^{(1,9)}$.

Besides fibers, the incorporation of nanoparticles into PMMA had gained attention in recent years. Of these, zirconia nanoparticles (NZ) used to reinforce and improve the physical and mechanical properties of PMMA/ZrO $\mathrm{Zr}_{2}$ nanocomposite (10,11). Recently, the effect of $\mathrm{NZ}$ on transverse strength of repaired denture base has been studied and revealed a significant increase in transverse strength especially with high NZ concentrations ${ }^{(12)}$.

The hybrid reinforcement systems have been carried out previously, to develop mixtures of different fibers, metal oxides, or fibers and fillers reported to produce improvements of the physical properties rather than adding them separately ${ }^{(7,13)}$.
The hybrid reinforcement can be generated by one of the following methods: adding a mixture of more than one type of fibers ${ }^{14}$, combining a variety of metal oxides and ceramics ${ }^{(15)}$, adding mixtures of metal oxides and fibers ${ }^{(16,17)}$, or using a combination of ceramic fillers ${ }^{(13,18,19)}$. A previous study reported promising results for flexural strength and toughness of acrylic resin reinforced with a hybrid mixture of fiber reinforcing materials ${ }^{(20)}$.

Dentures during function are subjected to different forms of stresses including compressive, tensile and shear stress. The intensification of stresses seems to be the main reason for intra-oral denture fractures ${ }^{(4)}$. The tensile test is expected to provide valuable information on the strength properties of the polymers ${ }^{(21)}$. Therefore, the tensile strength test was selected for this current study. Although the incorporation of NZ and GF into PMMA to improve its physical and mechanical properties has been done separately, to the knowledge of the authors, there were no studies done to evaluate the effect of NZ/GF mixture reinforcement on the mechanical properties of heat-cured denture base acrylic resin. Therefore, this study intends to evaluate the tensile strength of denture base acrylic resins reinforced with a mixture of $\mathrm{NZ} / \mathrm{GF}$ with different concentrations using the same experimental conditions. The null hypothesis in this study was that NZ/GF mixture did not enhance the tensile properties of denture base acrylic resin.

\section{MATERIALS AND METHODS}

\section{Molds preparation}

According to ISO standard \#1567 for denture base polymers ${ }^{(22)}$, dumbbell-shaped metal plates with dimensions $(32 \mathrm{~mm} \times 6 \mathrm{~mm} \times 2.5 \pm 0.03 \mathrm{~mm})$ were fabricated. The metal plates were invested in dental stone within the flask. After setting of stone, a separating medium was applied and the upper half of the flask was filled with a second layer of stone and closed. After complete setting of stone, the flask was opened and metal plates were retrieved creating 
mold spaces for acrylic resin packing. Both parts of the flask were cleaned with warm water, left to dry then coated with separating medium while the stone was still warm.

\section{PMMA-NZ/GF composite preparation}

\section{GF and NZ treatment}

In the present study, surface treatment of the NZ and GF with a bifunctional silane coupling agent [3-trimethoxysilyl propyl methacrylate, (TMSPM)] (Shanghai Richem International Co., Ltd. Shanghai, China) was performed. This agent has functional hydroxyl groups that bond to the fillers and fibers in addition to the presence of $\mathrm{C}=\mathrm{C}$ bonds which reacts with PMMA during polymerization and bonds it to NZ and GF ${ }^{(17,19)}$. GF (E-glass, Shanghai Richem International Co., Ltd., Shanghai, China) $3 \mathrm{~mm}$ in length and $12 \mu \mathrm{m}$ in diameter (Fig. 1A) were weighed using electronic balance (S-234; Denver Instrument) to create different concentrations of acrylic powder/GF mixtures (table 1). Pre-weighed GFs were soaked in 97\% TMSPM for $1 \mathrm{~min}$ at room temperature, followed by drying at $60^{\circ} \mathrm{C}$ for $24 \mathrm{~h}^{23}$. NZ (Shanghai Richem International Co., Ltd., Shanghai, China) with $99.9 \%$ purity, surface area of $9 \pm 2 \mathrm{~m}^{2} / \mathrm{g}$ and an average size of $30 \pm 2 \mathrm{~nm}$ (Fig. 1B) was treated with $0.3 \mathrm{~g}$ of TMSPM. This process allows for adequate adhesion between the resin matrix and $\mathrm{NZ}{ }^{(11)}$.

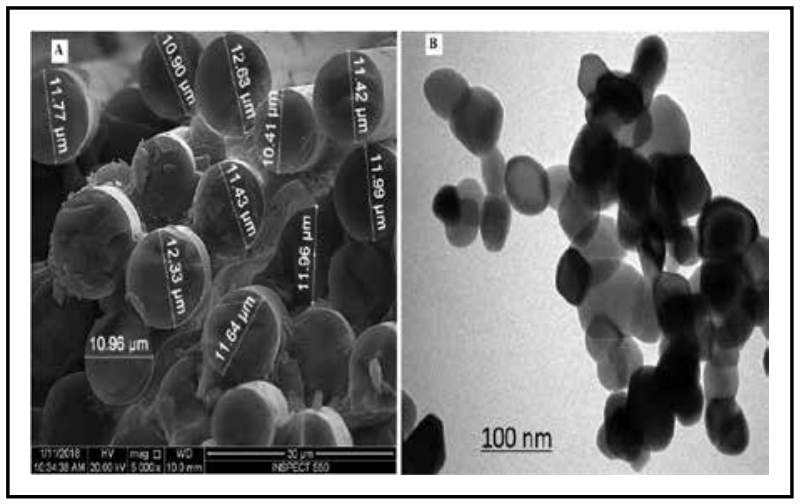

Fig. (1) (A) SEM image show diameter and size analysis of glass fibers (GFs); (B) TEM image show the size of zirconium oxide nanoparticles (NZr)
Table 1. Specimen grouping according to filler, fiber, and acrylic powder percentages

\begin{tabular}{cccc}
\hline Group & \multicolumn{2}{c}{ Percentage of filler/fiber/acrylic powder } \\
\hline Control & $0 \%(0 \% \mathrm{NZ}-0 \% \mathrm{GF})$ & $100 \%$ & Acrylic powder \\
\hline A & $5 \%(100 \% \mathrm{NZ}-0 \% \mathrm{GF})$ & $95 \%$ & Acrylic powder \\
\hline B & $5 \%(80 \% \mathrm{NZ}-20 \% \mathrm{GF})$ & $95 \%$ & Acrylic powder \\
\hline C & $5 \%(60 \% \mathrm{NZ}-40 \% \mathrm{GF})$ & $95 \%$ & Acrylic powder \\
\hline D & $5 \%(50 \% \mathrm{NZ}-50 \% \mathrm{GF})$ & $95 \%$ & Acrylic powder \\
\hline E & $5 \%(40 \% \mathrm{NZ}-60 \% \mathrm{GF})$ & $95 \%$ & Acrylic powder \\
\hline F & $5 \%(20 \% \mathrm{NZ}-80 \% \mathrm{GF})$ & $95 \%$ & Acrylic powder \\
\hline G & $5 \%(0 \% \mathrm{NZ}-100 \% \mathrm{GF})$ & $95 \%$ & Acrylic powder \\
\hline
\end{tabular}

\section{Nanocomposite preparation}

The amount of NZ+GF addition was fixed at $5 \mathrm{wt} \%$ of the acrylic powder. However, the ratio of $\mathrm{NZ}+\mathrm{GF}$ changed for every groups and is described in Table 1. The sum of treated pre-weighed NZ and GF percentages allocated per group were added to heat-cured acrylic resin powder in a plastic beaker, forming $100 \%$ of mixture for each group (95\% acrylic powder-5\% additive). Mixtures were stirred with a blender at a speed of $400 \mathrm{rpm}$ for $30 \mathrm{~min}$ to distribute NZ and GFs evenly within acrylic powder and obtain a homogenous color.

\section{Acrylic resin specimens preparation}

According to manufacturer' recommendation, the polymer is added to the monomer, mixed and left aside to reach dough stage then packed under pressure using pneumatic press. After one hour the clamped flask is placed in thermal curing unit (KaVo ElektrotechnischesWerk $\mathrm{GmbH}$, Leutkirch, Germany) for polymerization. The polymerization cycle starts with cold water heated to $70^{\circ}$ for 90 minutes followed by $100^{\circ} \mathrm{C}$ for 30 minutes. After curing, flasks are allowed to cool to room temperature, and the acrylic specimens were retrieved. Resin flashes were removed using 
arbor band and specimens were then finished and polished. A digital caliber was used to evaluate the specimens dimensions. Specimens not meeting the dimensional criteria were discarded. Approved specimens were kept in distilled water at $37^{\circ} \mathrm{C}$ for 1 week before testing.

\section{Conducting tensile strength test.}

For measurement of tensile strength of PMMANZ/GF and elongation at fracture, each specimen was fixed in a vice on a universal testing machine (Instron 8871; Instron Co., Norwood, MA, USA) with a load cell of $5 \mathrm{kN}$ and a chart speed $(20 \mathrm{~mm} /$ $\min )$. Then, the samples were tension loaded at a crosshead speed of $0.5 \mathrm{~mm} / \mathrm{min}$ until fracture. Failure load was recorded in Newton $(\mathrm{N})$. To calculate the tensile strength in $(\mathrm{MPa})$, the load at failure $(\mathrm{N})$ was divided by surface area $\left(\mathrm{mm}^{2}\right)$. The value of tensile strength was computed using the following formula: $\mathrm{TS}=\mathrm{F} / \mathrm{A}$, Where, $\mathrm{TS}=$ Tensile strength $\left(\mathrm{N} / \mathrm{mm}^{2}\right), \mathrm{F}$ $=$ Force at failure $(\mathrm{N}), \mathrm{A}=$ Area of a cross section at failure $\left(\mathrm{mm}^{2}\right)$. Testing procedures were performed at $23^{\circ} \mathrm{C}$ and $50 \%$ relative humidity ${ }^{(24)}$.

\section{Scanning electron microscopy (SEM)}

Surface fractographs were obtained using SEM (FEI, ISPECT S50, Czech Republic). Specimens were sputter coated (Quorum, Q150R ES, UK) with gold to overcome the non-conductive nature of acrylic. The specimens were then attached to a metallic stub using double-sided adhesive tape and images were taken at different magnifications to note important features about the nature of the failure.

\section{Statistical analysis}

The software package SPSS-20.0 (IBM,Armonk, NY) was used to perform statistical analysis. Tensile strength values were tabulated and transformed into arithmetic means and standard deviations (SD). Comparisons of tensile strengths between control and experimental groups were done using one-way
ANOVA and a Tukey-Kramer multiple-comparison test. A $p$-value $\leq 0.05$ was considered statistically significant.

\section{RESULTS}

\section{Tensile strength}

The mean values, standard deviations and significant differences are presented in Table 2. The addition of NZ significantly increases the tensile strength in comparison to control group $(P<0.05)$ while no significant difference was noted with GF addition $(P>0.05)$. The mixture of NZ/GF results in variation of tensile strengths depending on the ratio of NZ/GF. A significant increase in tensile strength value was found in group D $(50 \% \mathrm{NZ}$ $50 \% \mathrm{GF}$ ) which showed the highest strength value among hybrid groups (B,C,D,E,F). Moreover, there is no significant difference between groups C $(60 \% \mathrm{NZ}-40 \% \mathrm{GF}), \mathrm{E}(40 \% \mathrm{NZ}-60 \% \mathrm{GF})$, and F (20\%NZ-80\%GF) while group B (80\%NZ-20\%GF) showed a significantly low tensile strength value (37.78 $\pm 3.2 \mathrm{MPa})$.

\section{Elongation at break}

The mean values, standard deviation of elongation at break and the $p$-values are presented in Table 2. The results presented in Figure 2 and Table 2 shows no significant difference of elongation percentage at break between the control and group A. Furthermore, the values of elongation percentage decreased with decreased volume fraction of NZ/GF. This decrease was obvious for groups B (80\%NZ-20\%GF), C (60\%NZ-40\%GF), and $\mathrm{D}(50 \% \mathrm{NZ}-50 \% \mathrm{GF})$ while the percentage of elongation increased gradually as GF content increased as shown in groups E (40\%NZ-60\% GF), and $\mathrm{F}(20 \% \mathrm{NZ}-80 \% \mathrm{GF})$ and reaching the highest elongation value in group $\mathrm{G}(0 \% \mathrm{NZ}-100 \% \mathrm{GF})$. The only significant difference was found between group $\mathrm{G}$ and other reinforced test groups. 


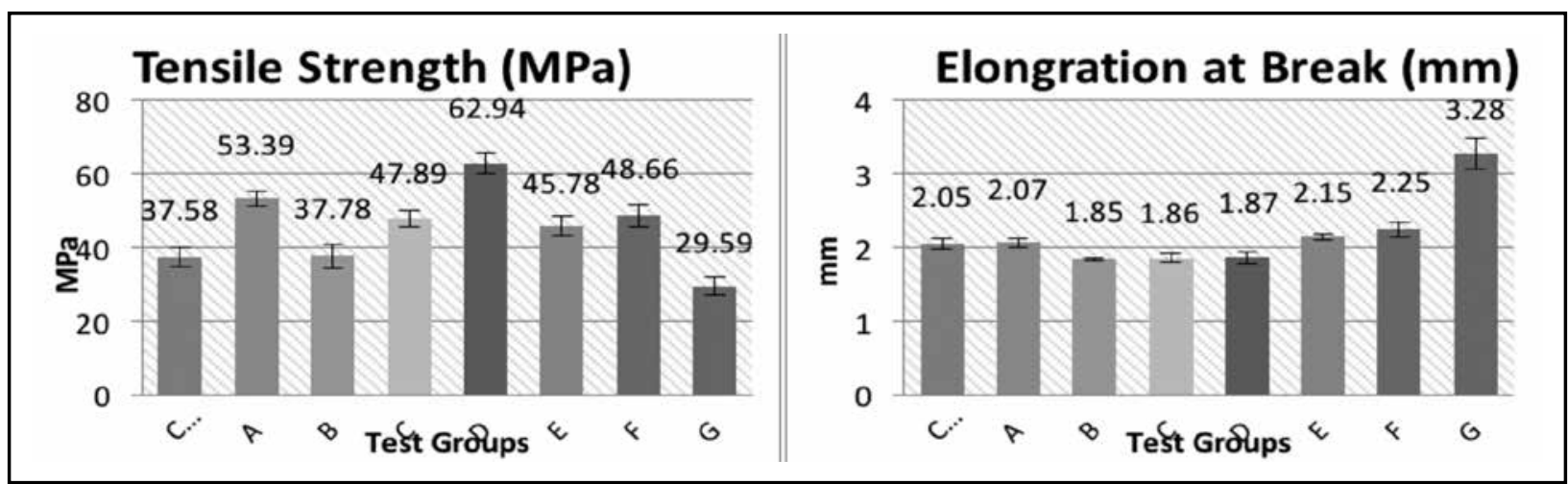

Fig. (2) Mean values and standard deviations for tensile strength and elongation at break of all test groups.

Table 2. Means, standard deviations, and significance levels of tensile strength $(\mathrm{MPa})$ and elongation at break $(\mathrm{mm})$ of all tested groups

\begin{tabular}{lll|ll|}
\multicolumn{3}{|c|}{ Tensile strength } & \multicolumn{2}{|l}{ Elongation at break } \\
Group & Mean \pm SD & Significantly different from & Mean \pm SD & Significantly different from \\
\hline Control & $37.58 \pm 2.7$ & A, D & $2.05 \pm 0.07$ & B,C,D,G \\
A & $53.39 \pm 1.9$ & Control, B, G & $2.07 \pm 0.06$ & G \\
B & $37.78 \pm 3.2$ & A,D & $1.85 \pm 0.02$ & Control, G \\
C & $47.89 \pm 2.2$ & D,G & $1.86 \pm 0.06$ & Control, G \\
D & $62.94 \pm 2.9$ & Control, B, C, D, E, F, G & $1.87 \pm 0.08$ & Control, G \\
E & $45.78 \pm 2.6$ & D,G & $2.15 \pm 0.04$ & G \\
F & $48.66 \pm 3.1$ & D,G & $2.25 \pm 0.10$ & G \\
G & $29.59 \pm 2.4$ & A, C, D, E, F & $3.28 \pm 0.21$ & Control, A, B, C, D, E, F
\end{tabular}

TEM results of $\mathrm{ZrO}_{2}$ nanoparticles: TEM imaging was carried out to measure the size of NZ particles. Different particles were measured by extracting the intensity profiles. The average size was estimated around $32 \pm 2 \mathrm{~nm}$ and a standard deviation of $11 \mathrm{~nm}$.

\section{Morphology of fractured surfaces (SEM)}

The morphology of polymer mixtures depends on the nature of constituents, ratios, addition methods, mixing, and processing techniques. The fractured surfaces of the specimens were examined using SEM (Fig. 3). Control specimens showed smooth surfaces (Fig. 3A) while NZ addition changed the surface topography where multiple lamellae and depressions were evident (Fig. 3B). It was found that the addition of GF to PMMA/NZ as in group B showed smooth mirror like appearance with small cluster formations of NZ and bundles of GF (Fig. $3 C, D)$. Altering NZ/GF ratio as in groups $C, D$, and $\mathrm{E}$ caused a rougher surface but with homogenous distribution of NZ and GF. Moreover, the cohesive and adhesive fractures of some GFs were noticed (Figs. 3E, F, G). Increasing GF ratio resulted in larger bundles of fibers surrounded by smooth resin matrix surface (Fig. 3G, H). Figure 4, showed different behaviors of GFs within the resin matrix, some GF bundles pulled out of the matrix (Fig. 4A) leaving large voids on opposing respective surfaces (Fig 4B). High magnification images (5000X), showed the distribution of NZ/GF with cohesive fracture and pull out of some GFs (Fig. 5A) while (Fig. 5B) showed GF bundles thin layers of acrylic resin matrix in between. 


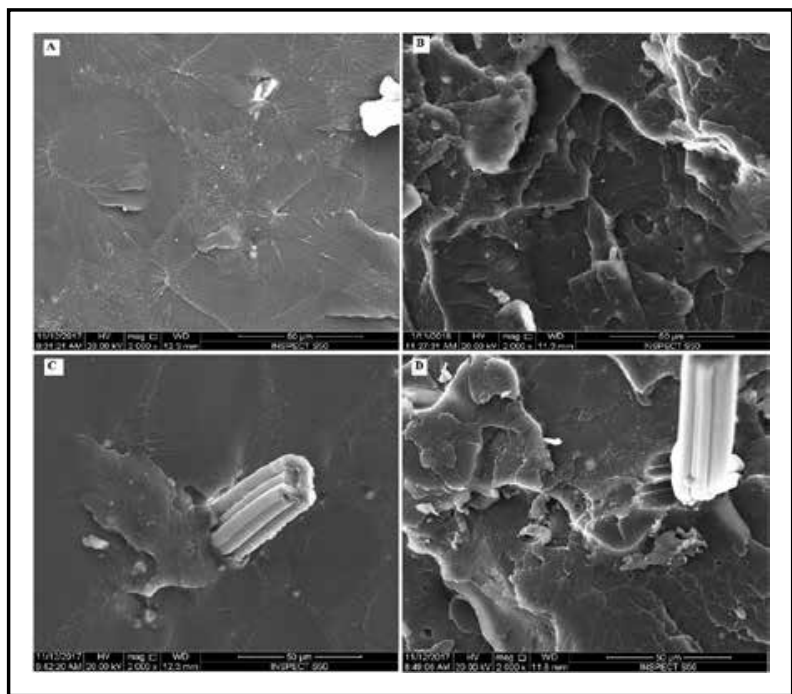

Fig. (3A-D) Representative SEM images. A) Unreinforced specimen; (B) Specimen reinforced with 100\% NZ$0 \% \mathrm{GF}(\mathrm{C})$ specimen reinforced with $80 \% \mathrm{NZ}-20 \% \mathrm{GF}$; (D) specimen reinforced with $60 \% \mathrm{NZ}-40 \% \mathrm{GF}$

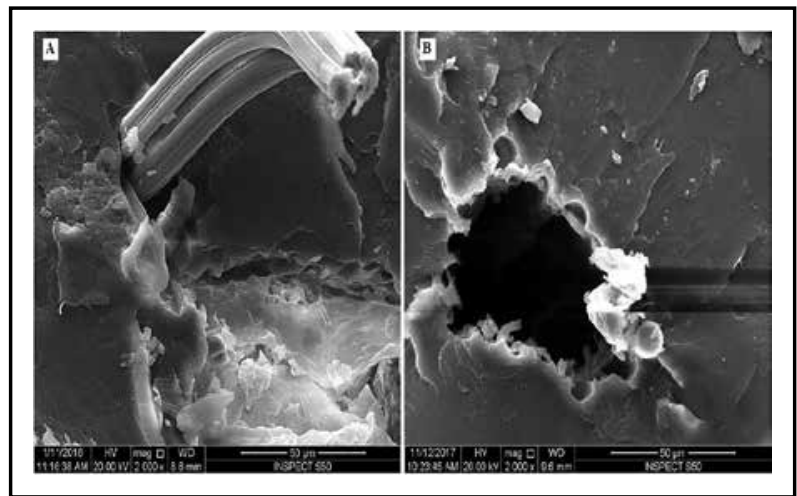

Fig. (4) Representative SEM images. (A) specimen with GF bundle formation; (B) specimen with void formation.

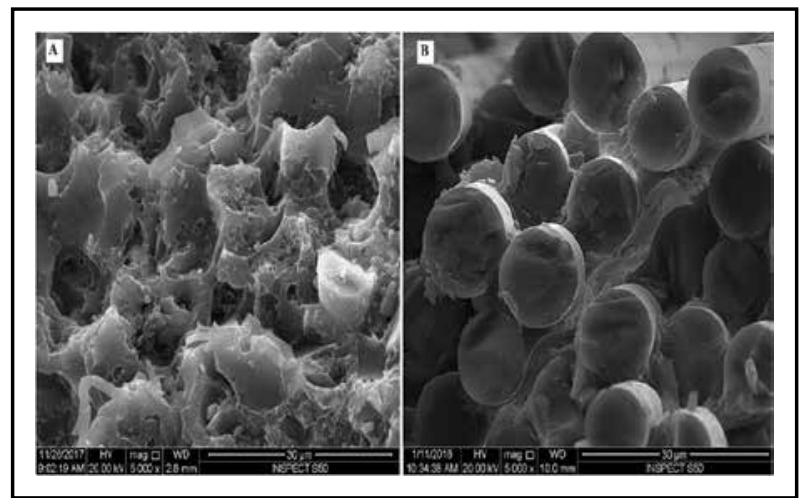

Fig. (5A-B) Representative SEM images with high magnifications (5000X). (A) GF distribution; (B) GF bundle formation

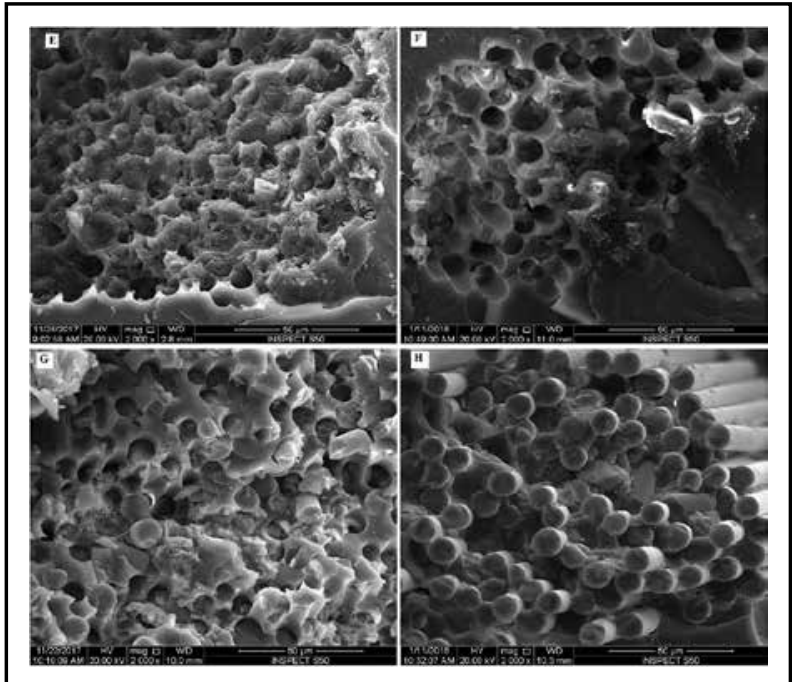

Fig. (3E-H) Representative SEM images. E) specimen reinforced with 50\% NZ- 50\%GF; (F) specimen reinforced with $40 \% \mathrm{NZ}-60 \% \mathrm{GF}$; (G) specimen reinforced with $20 \% \mathrm{NZ}-80 \% \mathrm{GF}$; $(\mathrm{H})$ specimen reinforced with $0 \% \mathrm{NZ}-100 \% \mathrm{GF}$.

\section{DISCUSSION}

Even with the advanced technology, hybrid systems were suggested to increase the properties of final products and subsequently increase the longevity of dentures for clinical use ${ }^{(7)}$. This could be obtained through one reinforcing material or a combination of two reinforcing materials within PMMA. This resulted in new polymeric materials with new properties that are in some situations better than those presented by single material reinforcement ${ }^{(7,25)}$. New PMMA/composite materials were obtained by incorporations of fibers, fillers and nano-fillers ${ }^{(7,26)}$. Among these additives are the commonly investigated GF and NZ used for the reinforcement of PMMA ${ }^{(1,4,7,26-28)}$. Both additives provided promising results in mechanical properties especially on the impact strength values of PMMA (7). Because of the lack of conclusive evidence concerning the use of NZ and GF reinforcement and their effects on the tensile properties, this in-vitro study was performed to determine tensile strength of PMMA after the addition of NZ, GF, or NZ/GF with different ratio. According to the results of this study, the combined reinforcement increased the 
tensile strength in comparison to the non-reinforced control specimens, confirming that the addition of different ratios of NZ/GF into the resin matrix would improve tensile strength. Therefore the null hypothesis was rejected.

The results of the current study showed that the addition of $\mathrm{NZ}$ increased the tensile strength of PMMA/NZ composite. This outcome is in agreement with previous studies confirming the positive effect of NZ addition to PMMA denture base material where it had a direct relation with flexural, impact, and tensile strengths ${ }^{(11,24,26)}$. The increase in tensile strength could be linked to a good dispersion of the NZ fillers within the matrix, and due to their nano-size, they have the capability of filling the matrix interstitially and improving the strength thereafter. The strong adhesion formed between the silane coupling agent covering the surface of the fillers and the resin matrix improves the nanocomposite mechanical properties (7,11). Moreover, the satisfactory distribution of nano- $\mathrm{ZrO}_{2}$ within the resin matrix allows for stress transfer from the weak PMMA matrix to the strong nano$\mathrm{ZrO}_{2}$ fillers. Another explanation for the increase in tensile strength may be attributed to the inherent feature of zirconia and its ability to transform from the tetragonal to monoclinic phase, namely transformation toughening, resulting in absorption of crack energy. Also, in this process, expansion of $\mathrm{ZrO}_{2}$ crystals occurs and places the crack under a state of compression, arresting its propagation ${ }^{(11,26,27)}$.

A previous study ${ }^{(28)}$ investigated the effect of titanium oxide nanoparticles addition on the tensile strength of denture base resin and found a decrease in tensile strength with the increase in filler content, which is in disagreement to the results of this study. The authors of that study attributed the decrease in tensile strength to agglomeration of the added fillers, acting as stress concentration areas within the matrix resulting in unfavorable mechanical properties of the composite material ${ }^{(6,28)}$. Also, the agglomerated fillers form loosely attached clusters affecting the mode of crack propagation, leading to reduction in tensile strength ${ }^{(26,28)}$. However, the results of this study exhibited an increase in tensile strength, even with high filler concentrations. These differences could be due to the nature of nanoparticles used or the effect of salinization on NZ distribution.

As seen in (Fig. 3B), the SEM micrographs showed good surface characteristic with $100 \%$ NZ$0 \% \mathrm{GF}$ addition (group A). The increased lamella with pits and fissures in group A in comparison to control group are representative of fracture mode of high strength materials. Additionally, no clustering of these nanoparticles was seen, validating a uniform distribution of nanoparticle. The SEM analysis showed nanoparticles filling inter-polymeric spaces, which in return stops the crack propagation yielding a stronger material ${ }^{(7,28)}$.

Reinforcing ability of the fibers is dependent on their adhesion to- and impregnation within- the polymer matrix ${ }^{(29)}$. To do so, the surface of GFs is treated with coupling agent to enhance bonding to the resin matrix ${ }^{(24,26,30,31)}$. Because the resin matrix and GF have different moduli, the two materials fall under different tensile strains. The strain in the fibers is less than that in the polymer matrix, and due to this strain difference, shear stresses are generated around the fibers along their long axis while the fibers are tensioned ${ }^{(31)}$. However, a fiber can withstand significant stresses up to fracture load and improve the strength of reinforced PMMA compared to unfilled one ${ }^{(12)}$. This positive effect of GF was obvious with all hybrid groups except group $B$. The results of the current study revealed that the addition of $5 \%$ GF as shown in group $\mathrm{G}(0 \% \mathrm{NZ}$ $100 \% \mathrm{GF})$ decreased the tensile strength compared to control group. This decrease in tensile strength values may be based on the random orientation of fibers or the bundle formations, which interfere with matrix continuity and stress transfer between fibers and polymer or within the same material ${ }^{(32,33)}$.

The reduction in the PMMA-composite's tensile strength may occur due to poor interface bonding between fiber bundles themselves as well as between 
the bundles and the matrix, resulting in poor adhesion and fiber pull-out, which are not good to transfer the tensile stresses ${ }^{(34)}$. This might help explain the observations in the SEM analysis where fibers were pulled out of the resin matrix under tension indicating weak adhesion. Although this study used salinized fibers, the defect in the bond at GF/matrix interface may be due to polymerization stress of GF surface and thermal stress ${ }^{(8)}$. SEM graphs confirmed that that GF were not well distributed within the polymer matrix with some clusters seen (Figs. 3 $\mathrm{G}, \mathrm{H})$. Images of SEM examination showed fibers pulling out of the resin matrix leaving voids and/or causing crack propagation from these pores under tensile loading. However, at higher magnifications, SEM fractographs showed no evidence of PMMA particles attached to the surface of fibers (Figs. 3H, 4A)

In hybrid composites (PMMA-NZ/GF), it can be noticed that the values of tensile strength changed when the ratio of NZ and GF in the PMMA composite material changed except for group B. Adding low percentage of GF to PMMA/ NZ significantly decreased the tensile strength in comparison to group A. This decrease in the tensile strength for group B could be attributed to GF bundles formation during mixing, packing or due to random orientation of glass fibers. Altering NZ/GF ratio from that of group $\mathrm{B}$, cause the tensile strength to increase as shown in groups $\mathrm{C}$ and $\mathrm{D}$. The tensile strength increased reaching the highest value in group D with an increase of $67 \%$ compared to nonreinforced PMMA. Therefore, the reinforcing effect of PMMA-NZ/GF composite was more effective. This was possible because of the synergistic effect of NZ and GF in enhancing the mechanical properties of PMMA ${ }^{(7)}$.

As presented in Table 2, changing NZ/GF ratio resulted in variation of tensile strength values. As the NZ or GF addition increased, (away from $50 \% \mathrm{NZ}-50 \% \mathrm{GF})$ a decrease in tensile strength was observed. When GFs amount increased more than $50 \%$, the tensile strength decreased. This can be seen in group $\mathrm{E}$ followed by group $\mathrm{F}$ and finally group $\mathrm{G}$ which showed the lowest tensile strength value (29.59 $\pm 2.4 \mathrm{MPa}$ ) compared to other test groups.

The amount of filler used to reinforce the acrylic resin is another important factor affecting the mechanical properties ${ }^{(35)}$. The percentage of filler used for reinforcement should be calculated properly to insure even dispersion into the resin matrix without interrupting its continuity ${ }^{(10)}$. This was confirmed by the results of this study, as the ratio was altered, the tensile strength was affected. Increasing the GF amount resulted in bundle formation and eventually a weak composite (Figs. $3 \mathrm{G} \& 3 \mathrm{H}$ ). In the same manner, increasing $\mathrm{NZ}$ resulted in a positive effect on the tensile strength of the composite material until the proper percentage of mixture was reached represented with group D with the highest strength values. All test groups except group B had significantly higher tensile strength values than control group confirming the favorable effect of hybrid reinforcement with $\mathrm{NZ}$ and GFs in agreement with previous studies ${ }^{(36,37)}$. The results of the present study confirmed that at certain percentages $(50 \% \mathrm{NZ}-50 \% \mathrm{GF})$, the tensile strength was at its maximum. Altering the ratio (increasing or decreasing) from this optimal level led to a decrease in tensile strength. This is confirmed by the SEM investigation of the fractured surfaces. A homogenous distribution of NZ particles within the resin matrix (Figs. $3 \mathrm{D}, \mathrm{E}, \mathrm{G}$ ) proves their positive effect in improving the tensile strength of nanocomposite. Furthermore, GFs fracture at the failure site revealed good adhesion between salinated GF and resin matrix (Figs. 3 $\mathrm{D}, \mathrm{E})$. However, when the amount of GFs was at its maximum $(0 \% \mathrm{NZ}-100 \% \mathrm{GF})$, GF congregated as bundles resulting in poor adhesion to resin matrix, which cause easy detachment from resin matrix leaving large voids (Figs. 4 A, B) At the end, the tensile strength deteriorated in comparison to other hybrid nanocomposite groups but was still higher than control group. 
In terms of elongation value at break, it was noticed that no change was seen in the values when NZ particles were added to PMMA resin while the addition of NZ/GF with different ratios decreased the elongation percentage when compared to control and PMMA/NZ specimens. The decrease in the elongation percentage depends upon the interface bonding between PMMA matrix and reinforcing materials, therefore, the decrease in the elongation percentage may be attributed to the formation of a strong PMMA-composite material ${ }^{(38)}$. Furthermore, it can be noted that the values of elongation percentage for groups $\mathrm{B}, \mathrm{C}$, and $\mathrm{D}$ are lower than those for group A. This is due to the higher mechanical strength of hybrid reinforcement with NZ-GF.

A good interfacial adhesion between resin matrix and added fibers is essential to prevent craze initiation and absorbs crack energy ${ }^{(33)}$. When GFs are added to the PMMA, the elongation percentage increased. This may be explained by the debonding or separation of the fibers from the resin matrix resulting in increased elongation. Previous results ${ }^{\left({ }^{(39)}\right.}$ coincide with the results of the current study where they found that as the tensile strength increased, the elongation at break decreased. PMMA/GF used in this study caused the maximum elongation in the composite at break.

Clinically, the improvement of the mechanical properties of the PMMA denture base through the addition of different reinforcing materials is required. As suggested in the current study, the combination of NZ and GF could be used to enhance PMMA. 95\%PMMA-2.5\%NZ-2.5\%GF hybrid reinforcement was the optimum level that produced a composite denture base material with adequate mechanical properties for removable prosthesis fabrication. The meticulous incorporation of those specific amounts resulted in better tensile strength of the final hybrid nanocomposite material.

The limitations of this study include: fixed concentrations of additions to the acrylic resin powder, only one type of denture base material was tested, one test conducted, and the testing conditions did not exactly mimic the oral environment. Therefore, further investigations with different concentrations, different types of denture base materials, and ageing procedures in conditions simulating the oral environment are recommended. Furthermore, the effect of those additives on other physical and clinical properties of the denture base resins must also be studied.

\section{CONCLUSION}

Within the limitations of the present study, the following conclusions could be drawn:

1. The addition of 5\% NZ increased the tensile strength of PMMA denture base material while the addition of 5\% GF didn't.

2. The elongation at break didn't change with the addition of $5 \% \mathrm{NZ}$, decreased with hybrid additions, and increased with 5\% GF addition.

3. Hybrid addition of NZ/GF to PMMA denture base material improved the tensile strength and the highest value was seen with the addition of $50 \% \mathrm{NZ} / 50 \% \mathrm{GF}$, which is recommended to be used as the proper ratio to improve the mechanical properties of final nanocomposites.

\section{REFERENCES}

1. Chen SY, Liang WM, Yen PS. Reinforcement of acrylic denture base resin by incorporation of various fibers. $\mathrm{J}$. Biomed. Mater. Res. 2001; 58: 203-8.

2. Jagger, DC, Harrison A, Jandt KD. The Reinforcement of Dentures. J Oral Rehabil 1999; 26: 185-94.

3. Jagger D, Harrison A, Jagger R, Milward P. The effect of the addition of poly (methyl methacrylate) fibres on some properties of high strength heat-cured acrylic resin denture base material. J Oral Rehabil. 2003; 30:231-5.

4. John J, Gangadhar SA, Shah I. Flexural strength of heat polymerized polymethyl methacrylate denture resin reinforced with glass, aramid, or nylon fibers. J Prosthet Dent. 2001; 86 : 424-7. 
5. Ruyter IE, Svendsen SA. Flexural properties of denture base polymers. J Prosthet Dent. 1980; 43:95-104.

6. Sehajpal SB, Sood VK. Effect of metal fillers on some physical properties of acrylic resin J Prosthet Dent. 1989; 61:746-51.

7. Gad MM, Fouda SM, Al-Harbi FA, Näpänkangas R, Raustia A. PMMA denture base material enhancement: a review of fiber, filler, and nanofiller addition. Int $\mathbf{J}$ Nanomedicine. 2017; 12:3801-12.

8. Kanie T, Fujii K, Arikawa H, Inoue K. Flexural properties and impact strength of denture base polymer reinforced with woven glass fibers. Dent Mater. 2000; 16:150-8.

9. Vallittu PK, Ruyter IE, Ekstrand K. Effect of water storage on the flexural properties of E-glass and silica fiber acrylic resin composite. Int J Prosthodont. 1998; 11:340-50.

10. Asopaa V, Suresha S, Khandelwala M, Sharmaa V, Asopab SS, Kairac LS. A comparative evaluation of properties of zirconia reinforced high impact acrylic resin with that of high impact acrylic resin. Saudi J Dent Resear. 2015; 2:146-51.

11. Ayad NM, Badawi MF, Fatah AA. Effect of reinforcement of high-impact acrylic resin with zirconia on some physical and mechanical properties. Rev Clı'n Pesq Odontol (Impr) 2008; 4:145-51.

12. Gad M., ArRejaie A.S.,Abdel-Halim M.S., Rahoma A. The Reinforcement Effect of Nano-Zirconia on the Transverse Strength of Repaired Acrylic Denture Base . Int J Dent, 2016 doi.org/10.1155/2016/7094056.

13. Salih SI, Oleiwi JK, Hamad QA. Investigation of fatigue and compression strength for the PMMA reinforced by different system for denture applications. Int $\mathrm{J}$ Biomed Mat Res. 2015; 3:5-13.

14. Sang-Hui YU, Yoon LE, Seunghan OH, Hye-Won CH, Yutaka OD, Ji-Myung BA. Reinforcing effects of different fibers on denture base resin based on the fiber type, concentration, and combination. Dent Mater J. 2012; 3:1039-46.

15. Safarabadia M,Khansarib NM, Rezaeic A. An experimental investigation of HA/AL2O3 nanoparticles on mechanical properties of restoration materials. Eng Solid Mech. 2014; 2:173-82.

16. Chen S, Liang W. Effects of fillers on fiber reinforced acrylic denture base resins. Mid Taiwan J Med. 2004; 9:203-10.

17. Muklif OR, Ismail IJ. Studying the effect of addition a composite of silanized Nano-A12O3 and plasma treated polypropylene fibers on some physical and mechanical properties of heat cured PMMA denture base material. J Bagh Coll Dent. 2015; 27:22-7.

18. Alhareb AO, Ahmad ZA. Effect of A12O3/ZrO2 reinforcement on the mechanical properties of PMMA denture base. J Reinf Plast Compos. 2011; 30:1-8.

19. Zhang XY, Zhang XJ, Huang ZL, Zhu BS, Chen RR. Hybrid effects of zirconia nanoparticles with aluminum borate whiskers on mechanical properties of denture base resin PMMA. Dent Mater J. 2014; 33:141-6.

20. Anusavice KJ. Phillip's Science of Dental Materials. (11th ed.). Missouri, United States of America. Saunders: Elsevier Inc; 2003 p.721-724.

21. Stafford GD, Smith DC. Flexural fatigue tests of some denture base polymers. Br Dent J. 1970 May 5; 128:442-5.

22. American Dental Association; Specification No. 12 for denture base polymer. J.A.D.A. 1975; 90: 451-458.

23. Moreno-Maldonado V, Acosta-Torres, LS, BarcelóSantana FH, Vanegas-Lancón RD, Plata-Rodríguez ME, Castaño VM. Fiber-reinforced nanopigmented poly (methyl methacrylate) as improved denture base. J. Appl. Polym. Sci., 2012126: 289-296.

24. Gad MM, Abualsaud R, Rahoma A, Al-Thobity AM, Al-Abidi KS, Akhtar S. Effect of zirconium oxide nanoparticles addition on the optical and tensile properties of polymethyl methacrylate denture base material. Int $\mathbf{J}$ Nanomed. 2018; 13:283-292.

25. Salih SI, Salih WB, Mohammed MS. Characterization and compare between two groups of hybrid nanocomposite materials prepared from ternary polymer blend. Adv Nat and App Sci. 2016; 10: 143-54

26. Gad MM, Rahoma A, Al-Thobity AM, ArRejaie AS. Influence of incorporation of $\mathrm{ZrO} 2$ nanoparticles on the repair strength of polymethyl methacrylate denture bases. Int J Nanomed. 2016; 11:5633-43.

27. Kenneth JA. Phillips' Science of Dental Materials, Saunders, Philadelphia, Pa, USA, 11th edition, 2003.

28. Chatterjee A. Effect of nano-TiO2 addition on poly methyl methacrylate. J Appl Polym Sci 2010; 16:3396-407.

29. Lassila LVJ, Vallittu PK. The Effect of Fiber Position and Polymerization Condition on the Flexural Properties of Fiber-Reinforced Composite. J Contemp Dent Pract 2004; 2:14-26.

30. Solnit GS. The effect of methyl methacrylate reinforcement with silane-treated and untreated glass fibers. J Prosthet Dent. 1991; 66:310-314. 
31. Vallittu PK. Curing of a silane coupling agent and its effect on the transverse strength of auto polymerizing polymethylmethacrylate-glass fiber composite. J Oral Rehabil. 1997; 24:124-30.

32. Kilfoil BM, Hesby RA, Pelleu GB. The tensile strength of composite resin reinforced with carbon fibers, J Prosthet Dent 1983; 50:40-43.

33. Krause WR, Park SH, Straup RA. Mechanical properties of BIS-GMA resin short glass fiber composites. J Biomed Mater Res. 1989; 23:1195-211.

34. Hemanth R, Sekar M, Suresha B. Effects of Fibers and Fillers on Mechanical Properties of Thermoplastic Composites. Ind J Adv Chem Sci 2014; 2: 28-35.

35. Hong XY, Wei L, Wei Q. Nano technology: Basic concepts and Definition. Clin chem, 2003; 40:1400.
36. Vojdani M, Khaled AR. Transverse Strength of Reinforced Denture Base Resin with Metal Wire and E-Glass Fibers. J Dent, 2006; 3:167-72.

37. Asar NV, Albayrak H, Korkmaz T, Turkyilmaz I. Influence of various metal oxides on mechanical and physical properties of heat-cured polymethyl methacrylate denture base resins. J Adv Prosthodont 2013; 5: 502.

38. Sreekanth MS, Bambole VA, Mhaske ST, Mahanwar PA. Effect of concentration of Mica on Properties of Polyester Thermoplastic Elastomer Composites. J Min Mat Charact Eng. 2009; 8: 271-82.

39. Feng Yang, Gordon L. Nelson. PMMA/Silica Nanocomposite Studies: Synthesis and Properties. J App Poly Sci, 2004;91: 3844-50. 